\title{
Not as good as we need it to be
}

\author{
Chronic Condition: Why Canada's \\ Health Care System Needs to be \\ Dragged into the 21st Century \\ Jeffrey Simpson \\ Allen Lane; 2012
}

$\mathrm{T}$ he first law of health care improvement is that every system is perfectly designed to get the results it gets. Jeffrey Simpson, arguably Canada's pre-eminent newspaper columnist, explains why we get the results we do in Chronic Condition. $\mathrm{He}$ is correct to start from the position that our results are good, but not great. As Simpson puts it, our system is not as good as it could be, not as good as it should be, not as good as many of us think it is, and not as good as we need it to be.

The most interesting and useful part of Simpson's book is the first third, which chronicles the evolution of our patchwork health care system and provides answers to many frequently asked questions. Why are most physicians in Canada paid on a fee-for-service basis even though salaries predominate in so many other countries? In large part because of a stand-off between two friends, Emmett Hall, the Supreme Court judge who chaired a Royal Commission on health care in the 1960s, and David Baltzan, the progressive Saskatchewan physician who supported medicare, but drew the line at eliminating fee-for-service. Why did we need the Canada Health Act? Provincial governments were struggling with the effects of economic stagnation in the 1970s and became incapable of increasing physician fees in line with inflation. More and more physicians opted out of provincial health insurance plans and began to bill patients directly. The consequences for patients who could not afford the higher fees were so obvious that not a single member of Parliament voted against the legislation. Simpson's historic survey reminds us not only that individuals can and do shape history,

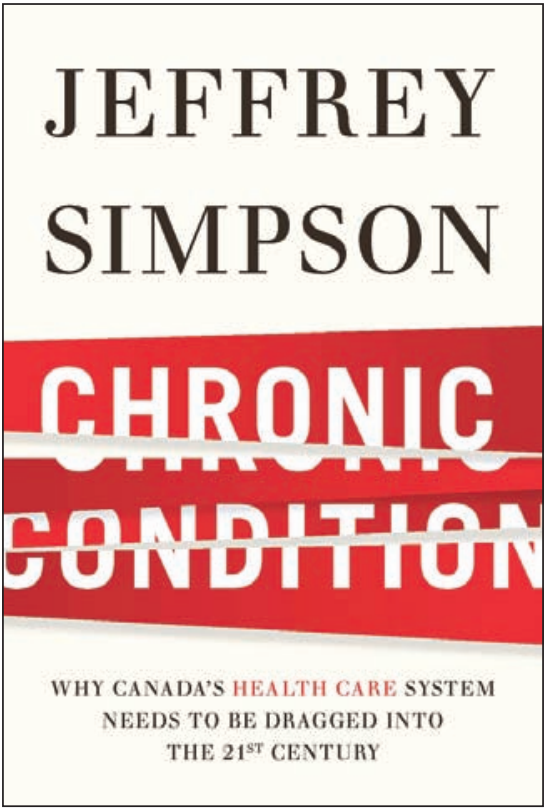

but that the actions of individuals must be considered within the context of broader economic and social change.

In preparing to write this book, Simpson spent a week in an Ottawa hospital, read and travelled widely, and spoke with many health care professionals and academics. His careful examination has allowed him to accurately diagnose some of the chronic conditions that ail our system: access to prescription drugs and home care is far from universal, patients with complex medical problems are too frequently cared for in hospital rather than in the community, and we overpay for both brand-name and generic prescription drugs.

Many of Simpson's proposed solutions are sensible. Physicians should be more accountable to hospitals or regional health authorities. Low-risk surgical procedures should be moved out of large hospitals that are better suited for complex care. Public funders should consider private providers when they can offer equivalent or superior quality at a lower cost. Primary care should be available in the evenings and on weekends.

The book's main weakness, however, is its reliance on anecdote rather than more rigorous reviews of the evi- dence. In particular, this leads Simpson to repeatedly make misleading claims about the advantages of the private sector. For example, he writes that Canadian Radiation Oncology Services, a private company that had a contract with the Ontario government between 2001 and 2003, provided care $60 \%$ more efficiently than public hospitals. In fact, the company was paid more to provide care than public providers were. These two facts are not necessarily contradictory - the operating costs incurred by the private provider were lower than in the public sector, but the price paid by the government was higher. The difference, of course, was mostly profit. There is nothing inherently wrong with profit, but to emphasize the reduced costs borne by the private provider without mentioning the higher prices paid by taxpayers is disingenuous. Simpson is deeply critical of those mythical creatures who wish to maintain the status quo, and emptily refers to those who defend medicare as being "unreconstructed." But he turns a blind eye to those who have privatized and profited at public detriment in other countries, and ignores a series of systematic reviews comparing for-profit and nonprofit care.

Despite these imperfections, we owe thanks to Simpson for turning his attention to the public policy issue that Canadians care about most. The debate about how we finance, organize and deliver health care will never be over, nor should it be. The corollary of the first law of health care improvement is that we must continually redesign our system to improve our results. Simpson is right that the status quo is not good enough. As the CEO of my hospital likes to say, better has no limit.

\section{Irfan A. Dhalla MD MSc \\ Assistant professor \\ Department of Medicine \\ University of Toronto \\ Toronto, Ont.}

CMAJ 2012. DOI:10.1503/cmaj.121191 